DOI 61

\title{
CORRELATION BETWEEN CLINICAL DIAGNOSES WITH QUALITATIVE LEVELS OF SERUM METHANOL AND CORRELATION BETWEEN INDIRECT LABORATORY EXAMINATION WITH QUANTITATIVE LEVELS OF SERUM METHANOL IN METHANOL INTOXICATION PATIENTS
}

\author{
Rintawan Corona ${ }^{1 *}$, Prasetyadjati $\mathrm{Ari}^{2}$, Haedar $\mathrm{Ali}^{2}$, Rasyid Harun $\mathrm{Al}^{3}$ \\ ${ }^{1}$ Resident of Medical of Specialist Doctoral Program, Faculty of Medicine, \\ University of Brawijaya, Indonesia \\ ${ }^{2}$ Staff of the Medical Emergency Department, Faculty of Medicine, \\ University of Brawijaya, Indonesia \\ ${ }^{3} \mathrm{Head}$ of the Department of Public Health, Faculty of Medicine, University of Brawijaya, \\ Indonesia \\ *E-mail: corona.rintawan@gmail.com
}

\begin{abstract}
Around the world, cases of methanol intoxication are still common, especially in countries that prohibit the sale of alcohol freely. The mortality rate due to methanol intoxication is very high. Quick and precise diagnosis is still a challenge because special laboratory tests are needed to detect the presence of methanol in the blood. General practitioners often rely solely on clinical diagnosis and simple laboratory examinations to help diagnose methanol intoxication. This study aims to determine correlation between clinical diagnosis with qualitative levels of serum Methanol and correlation between indirect laboratory examination $(\mathrm{pH}$, anion gap, lactate and blood osmolality) with quantitative levels of serum methanol in methanol intoxication patients. The research design used was analytic observational with cross sectional approach. The study subjects were patients with a suspected diagnosis of methanol intoxication in Dr. Saiful Anwar, Malang, East Java during the period of July 2016 until July 2018. The location of the study was at RSU Dr. Saiful Anwar, Malang, East Java; and forensic laboratories of East Java Regional Police, Surabaya. Data was recorded in a special registry which was then carried out by the Spearman correlation test to test the correlation between indirect laboratory results $(\mathrm{pH}$, anion gap, lactate and osmolality) with quantitative levels of Methanol. The Fisher Exact test and Chi square test were used to examine the relationship between clinical diagnosis and qualitative test of serum methanol. The analysis program used is SPSS 20 . Total 32 cases suspected of methanol intoxication, 3 cases in the exclusion criteria. Out of 29 cases, it was more common in men (83\%) than women with mean age of 28.75 years. Fisher's Exact test results in $p=0.692$ or greater than $\alpha=0.05$, so it was stated that there was no significant difference between clinical diagnosis and qualitative levels of serum methanol. From diagnostic tests, clinical diagnosis has a sensitivity value of $86.4 \%$ and a positive predictive value of $76 \%$ but its specificity value is only $14.3 \%$ and negative predictive value is only $25 \%$. Spearman correlation test showed that there was a significant relationship between serum methanol levels with $\mathrm{pH}(\mathrm{p}=<0.01)$, lactate $(p=0.012)$, anion gap $(p=<0.01)$ and osmolality $(p=0.012)$. There was no significant relationship between clinical diagnosis and qualitative levels of serum methanol. There is a significant relationship between $\mathrm{pH}$, lactate, anion gap and serum osmolality with quantitative levels of methanol.
\end{abstract}

\section{KEY WORDS}

Methanol intoxication, formic acid, diagnostic tests, indirect laboratory examination, serum methanol.

Methanol poisoning can be caused through various methods; inhalation, percutaneous absorption (contact with skin), contact with eyes and ingestion / orally. In Indonesia the most frequent cases of methanol poisoning are by drinking (ingestion). Usually methanol poisoning is obtained as a result of the mixed ingredients of alcohol which is more commonly 
known as "oplosan alcohol" or alcohol concoctions. During 2014 there were cases of poisoning totaling 196 people with as many as 73 deaths (Mulyadi, 2014). According to the WHO, methanol poisoning frequently occurs in countries with prohibit the sale of alcohol freely, which triggers the sale of illegal alcohol by the wrong distillation process and the formation of high levels of methanol (Poznyak Poznyak, 2014). Methanol consumed in large quantities will be metabolized by the body to produce formaldehyde and formic acid. It is this metabolic outcome that results in multiple organ damage and results in death. Formic acid and formaldehyde formed by methanol metabolism cause metabolic acidosis conditions that interfere with the metabolic system of cells and organs.

Symptoms of intoxication methanol include headache, dizziness, overia, visual impairment, drunk, shortness of breath until decreased consciousness. This symptom depends on the amount of metabolic results as a result of methanol being consumed. The more methanol that enters the digestive tract, the more metabolic results will be and the more severe the symptoms that appear even cause death.

In handling the cases of methanol poisoning, the diagnosis is very important because the speed and accuracy of the diagnosis will affect the speed and accuracy of therapy. Enforcement of a diagnosis of methanol poisoning is done by checking serum methanol levels in the patient's blood. But unfortunately this examination is often not available in most ED so that other laboratory tests are needed that can support the diagnosis and are more available in hospitals (WHO, 2014). This also happens in Indonesia, in the process of establishing a diagnosis of methanol poisoning there are obstacles one of which is confirmation of laboratory results to test for the presence of methanol in the blood serum of patients because there are very few laboratories that can check serum methanol. Laboratory examinations that are usually available in the ED for examination of emergency patients are routine blood gas, electrolyte and blood pressure analysis. This study analyzed the relationship between indirect laboratory tests $(\mathrm{pH}$, anion gap, osmolality and lactate) with serum methanol levels and the relationship of clinical diagnosis with direct laboratory examination (serum methanol quality test). From this study it is hoped that it can help the clinicians in diagnosing patients with suspected methanol poisoning.

\section{LITERATURE REVIEW}

Methanol Biochemistry. The popular name of methanol is wood alcohol (because the first distillation process was from wood in 1926 (Methanol Institute)). The synonymous names of other methanol are methyl alcohol, carbinol, columbian spirit, spirit piroligneus, wood spirit, heet, methyl hydrate, methyl hydroxide, monohidroxymethane, methylol. In its development today it is known as hooch / moonshine (USA), chang'aa (Kenya), tonto/waragi (Uganda), tuak/tapai (Malaysia), samogon (Russia), and talla (Ethiopia) (Poznyak, 2014). In Indonesia, it is called as "miras oplosan".

The nature of methanol is clear, colorless, taste and smell depending on the level of purity to spicy/sharp (Salocks, 2003; Nand, 2014). Methanol is commercially used as a solvent in the antifreeze industry for car radiators; fuel mixture material; fuel for camping stoves; softener for pyrrolin plastics; solvents for paints and varnishes; ingredients for paint removal; mixed materials for car windshield washing liquids, model aircraft fuels, balm liquids, and ink; denaturant for ethanol and as an alternative fuel for motorcycles (Salocks, 2003).

Methanol metabolism. The metabolic process of ethanol is the same as methanol in terms of the enzymes involved, therefore the non-metabolic process of methanol clearance is also considered the same as ethanol, namely through the breath / lungs, sweat and urine. The percentage of the amount of methanol released through this non-metabolic mechanism is around $10-13 \%$ and a small amount which will also be excreted through urine as formic acid but mostly released as carbon dioxide (Dorokhov, 2015; Shusterman, D. and Ambre, J., 1997).

Methanol is rapidly absorbed by the stomach and reaches blood peak levels of 30-60 minutes depending on the amount of food in the stomach (White, 2008, Cohen, JP, 2016; 
Jammalamadaka, 2010), but cannot be found completely in the blood due to metabolism by enzymes Alcohol Dehydrogenase (ADH) and the first bypass by the liver become formaldehyde. After that formaldehyde will be changed by the enzyme aldehyde dehydrogenase to formic acid. And then formic acid will be oxidized by catalase to carbon dioxide (Dorokhov, 2015) (Figure 1).

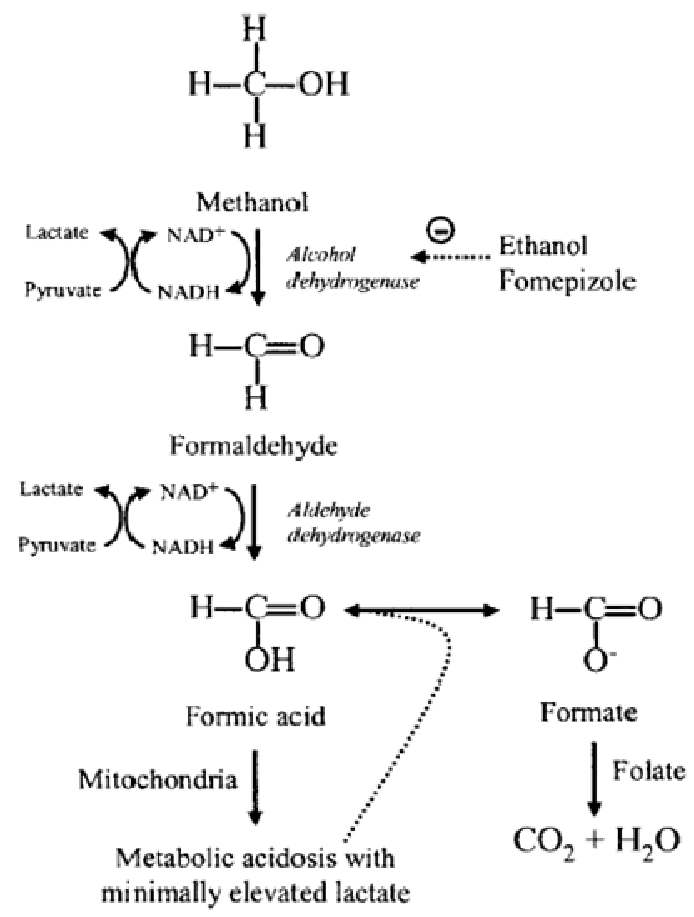

Figure 1 - Oxidized of formic acid to carbon dioxide

Formaldehyde and formic acid have toxic properties stronger than methanol itself. It is formaldehyde and formic acid that are a source of problems for the body and cause severe metabolic acidosis (Hodgson, 2004; Rao, 2010; Cohen, JP, 2016; Mokhlesi, 2007; Kaley, 2003; Fulde, 2014; White, 2008; Raissi, 2010; Kraut, 2008; Nand, 2014; Hoffman, 2007; Sherman, 2014; Manahan, 2002). The smallest lethal dose in adult humans is $15 \mathrm{ml}$ for $40 \%$ methanol while $4 \mathrm{~mL}$ of pure methanol will cause blindness (White, 2008).

At the cellular level, there is some damage based on the metabolic process of methanol oxidation. First, the oxidation of methanol will produce the formation of reactive oxygen species (ROS) which will contribute to cell damage (Dorokhov, 2015). Second, formaldehyde acid which is formed due to the oxidation of methanol will penetrate the cell membrane easily and is neurotoxic which causes damage to memory and learning ability (Dorokhov, 2015). Third, formic acid inhibits the cytochrome oxidation chain, thereby inhibiting oxidative phosphorylation and results in anaerobic metabolic processes so that lactate production increases and exacerbates metabolic acidosis that has emerged due to formic acid formation (Hoffman, 2007). In addition to formic acid that can damage eye cells directly, disturbances in eye nerve cells can also occur through the mechanism of retinal retinol-aldehyde oxidation inhibition by the presence of methanol in the blood (Dorokhov, 2015). So besides formaldehyde acid, formic acid is also responsible for the occurrence of metabolic acidosis through the mechanism of: a) the nature of the formic acid itself and b) the inhibition of metabolic phosphorylation oxidation so that the anaerobic metabolism that produces lactate results in lactic acidosis. In addition, metabolism of methanol increases the $\mathrm{NADH} / \mathrm{NAD}+$ ratio which encourages the conversion of pyruvate to lactate and increases the degree of lactic acidosis present.

At the organ level, there are two organs that are the main target of damage due to methanol metabolism, the eye and brain nerve tissue. In the eye's nerve tissue, damage 
occurs due to necrosis in the orbital part of the eye's nerves. In non-fatal cases, this damage is recovered after therapy, although central and peripheral scotomas continue to appear, depending on several factors (Shusterman, D. and Ambre, J., 1997). In the central nervous system, damage occurs in the basal ganglia region, which is in the form of bilateral basal ganglia lesions (most commonly putamen, whereas the caudate nucleus is rare) (Hoffman, 2007). Lesions that occur in the form of edema (White, 2008) until bleeding in fatal cases (Shusterman, D. and Ambre, J., 1997). PH levels that go down will also trigger the formation of formic acid that is not dissociated, and this form will be easier penetrate the blood brain barrier and cause more severe damage to the central nervous system and the optic nerve above (Cohen, JP, 2016; Rao, 2010).

Symptoms and Clinical Signs. Methanol poisoning can be through inhalation, ingestion and skin; but the most common is through ingestion or drinking. Methanol is a mild irritant to mucous membranes, respiratory tract and eyes. While the effect on the skin is dry and broken. The heaviest toxic effect of methanol is when taken in large quantities which will cause systemic effects. Methanol in the blood is not a cause of the emergence of clinical symptoms but its metabolite products are formaldehyde and formic acid which are toxic (Hodgson, 2004). Clinical symptoms of methanol poisoning will occur after 12-24 hours but symptoms can appear earlier (40 minutes-1 hour) if methanol is taken in large amounts or mixed with ethanol (Rao, 2010; White, 2008).

Symptoms that arise due to high levels of methanol in beverages include general symptoms, gastrointestinal, cardiovascular, respiratory system, central nervous system, excretory system, and visual system. Common symptoms are headache, dizziness, muscle vertigo and weakness (Rao, 2010). Gastrointestinal symptoms that appear begin nausea, vomiting, abdominal pain and pancreatitis. Cardiovascular symptoms that arise are tachycardia and hypotension which will lead to shock and hypothermia. In the respiratory system the symptoms are tightness and tachypnea as compensation for metabolic acidosis which if left without therapy will end in respiratory failure. Vision system disorders that arise from blurry eyes to blindness with signs of papilledema, non-reactive nystagmus and mydriasis at the final stage. In the central nervous system, the complications that occur are delirium, headache, vertigo, dizziness, convulsions, and coma, which last for 2-3 days (White, 2008; Hoffman, 2007; Mokhlesi, 2007).

Laboratory Test. Laboratory results that are considered to be helpful in establishing the diagnosis of methanol poisoning are of two types, that is direct and indirect examination (Shusterman, D. and Ambre, J., 1997). Direct examination is an examination aimed at measuring the level of methanol in the blood while the indirect one is an examination intended to measure the level of its metabolites or the effects of methanol metabolism.

On direct examination, the levels of methanol will be measured through examination of urine, breath, and blood. Methanol levels in the blood are more commonly examined. Endogenous methanol levels in the blood are normally $0.05 \mathrm{mg} / \mathrm{dL}$. Methanol levels of $>20$ $\mathrm{mg} / \mathrm{dL}(6 \mathrm{mmol} / \mathrm{L})$ are considered as the limit for the appearance of clinical symptoms in methanol poisoning patients. Levels above $50 \mathrm{mg} / \mathrm{dL}(>16 \mathrm{mmol} / \mathrm{L})$ can cause visual symptoms and levels $>150-200 \mathrm{mg} / \mathrm{dL}$ (> 47-62 mmol / L) will increase the risk of fatality or death (Cohen, J.P, 2016).

On indirect examination, the measured levels are $\mathrm{pH}$, anion gap, osmolal gap and lactate. Examination of blood gas analysis will show metabolic acidosis with a high anion gap or HAGMA (high anion gap metabolic acidosis) and high osmolal gap. (Hoffman, 2007; Mycyk, 2015; Raissi, 2010; Cohen, J.P, 2015; White, 2008). Although there are several cause of HAGMA and a high cause of osmolal gap (see table 1) and a definite diagnosis is determined by serum methanol levels; in patients with cases of decreased consciousness, visual impairment or metabolic acidosis, examination of anion gap and osmolal gap can help clinically in diagnosis. (Cohen, J.P, 2015; White, 2008). Osmolal gap is determined based on the calculation between measured osmolality minus calculated osmolality. Because methanol is active osmotically it will contribute to the calculated osmolality. Osmolal gap will reach the highest point in the early hours of methanol and will decrease with time due to methanol metabolism, so that patients who do not arrive at the initial moment will show a 
normal osmolal gap value. Osmolal gap levels are considered high when above 10-15 mmol / L while osmolal gap levels $>50 \mathrm{mmol} / \mathrm{L}$ strongly support toxic alcohol poisoning. The value of osmolality can also be calculated in helping to diagnose methanol intoxication because 1 milligram / dL $(0.3 \mathrm{mmol} / \mathrm{L})$ methanol will increase serum osmolality by $0.34 \mathrm{mOsm} / \mathrm{kg} \mathrm{H} 2 \mathrm{O}$ (Cohen, JP, 2015). Lactate levels in patients with methanol poisoning, in addition to direct conversion from NADH, can also increase due to anaerobic metabolic processes caused by disruption of the oxidative phosphorylation process (Mycyk, 2015).

Table 1 - Differential Diagnosis of HAGMA Causes

\begin{tabular}{|ll|}
\hline Category & \\
\hline Renal Failure & Uremia \\
\hline $\begin{array}{l}\text { Lactic } \\
\text { acidosis }\end{array}$ & $\begin{array}{l}\text { Septic, shock, liver disease, isoniazid, iron, carbon monoxide, methemoglobin, metformin, and } \\
\text { cyanide }\end{array}$ \\
\hline Ketoacidosis & Diabetic ketoacidosis, alkoholic ketoacidosis, starvation ketoacidosis \\
\hline Ingestion & Metanol, ethylene glycol, salicylates \\
\hline
\end{tabular}

Source: Cohen, J.P, 2015.

Management. Management of methanol poisoning in principle is to carry out initial resuscitation, help the heart of the lungs, improve acidosis, prevent the formation of toxic metabolites and improve the cleaning of parent substances and toxic metabolites (Cohen, J.P, 2016).

Gastric lavage can only be done if the patient comes to the hospital within $30-60$ minutes after taking methanol. There is also no evidence that guarantees its success. While diuretics will actually endanger patients with risk of pulmonary edema and Acute Respiratory Distress Syndrome / ARDS (White, S.R., 2008).

Acidosis correction can improve the patient's clinical condition because the acidosis can worsen the toxic effects of formic acid, including visual disturbances that occur, besides alkalinization can change the form of undissociated formic acid to dissociate (lower toxic effects), and can accelerate formic acid clearance by mechanism decreases reabsorption in the proximal renal tubule (Hoffman, 2007). Sodium bicarbonate can be given to maintain $\mathrm{pH}>$ 7.30. Sodium bicarbonate can be given intravenously repeatedly with an initial bolus followed by an infusion or just by IV (White, S. R., 2008).

The provision of methanol competitors such as fomepizole and ethanol can prevent and protect sufferers from fatal toxic effects such as blindness, kidney failure or decreased consciousness. Fomepizole has a much stronger affinity (500-1000x) against alcohol dehydrogenase enzymes than ethanol or methanol. The advantages of fomepizol are fewer side effects than ethanol administration but prices are a major limitation (see Table 2). The initial dose given is $15 \mathrm{mg} / \mathrm{kg}$ IV for 30 minutes, followed by an additional dose of $10 \mathrm{mg} / \mathrm{kg}$ given for 30 minutes every 12 hours. Fomepizole must be continued until methanol levels $<6$ $\mathrm{mmol} / \mathrm{L}$ and metabolic acidosis are resolved (Cohen, J.P, 2016). The administration of fomepizole has also been shown to have fewer side effects than ethanol (Brent, J., 2015).

If fomepizole is not available, ethanol can be given directly or orally. The target ethanol level is $100-150 \mathrm{mg} / \mathrm{dL}(22-33 \mathrm{mmol} / \mathrm{L})$ so that it can effectively form toxic metabolites from methanol. The initial dose of ethanol given is $800 \mathrm{mg} / \mathrm{kg}(10 \mathrm{~mL} / \mathrm{kg}$ IV fluid $10 \%)$ while the maintenance dose depends on the patient but is usually around $100 \mathrm{mg} / \mathrm{kg}$ per hour $(1.2$ $\mathrm{mL} / \mathrm{kg}$ per IV $10 \%$ ). The initial oral dose is $1.5-2 \mathrm{~mL} / \mathrm{kg}$ followed by a maintenance dose of $0.2-0.5 \mathrm{~mL} / \mathrm{kg}$ per hour using 80 -proof fluid. Serum ethanol is checked every 1-2 hours and maintained at $100 \mathrm{mg} / \mathrm{dL}$ because of the drunk and respiratory depression effect. Administration of ethanol IV $10 \%$ require central venous access because of its hyperosmolar and irritating effect (Cohen, J.P, 2016).

Hemodialysis can quickly remove methanol and its metabolic toxic, while improving metabolic acidosis. Hemodialysis is needed in emergency conditions for patients with severe acidosis $(\mathrm{pH}<7.25, \mathrm{AG}>30 \mathrm{mEq} / \mathrm{L}$ and / or $\mathrm{BE}<15)$, visual changes, unstable hemodynamics, or kidney failure (Cohen, J.P, 2016). 
Table 2 - Comparison of Fomepizole and Ethanol as Methanol Poisoning Therapy

\begin{tabular}{|c|c|c|}
\hline Compound & Advantages & Disadvantages \\
\hline Fomepizole & $\begin{array}{l}\text { High affinity for alkohol dehydrogenase } \\
\text { (approximately } 500 \text { to } 1000 \text { times more than } \\
\text { etanol) } \\
\text { Effective at relatively lo serum concentrations } \\
\text { Minimal adverse effect } \\
\text { No effect of mentation that could confuse } \\
\text { interpretation of clinical course } \\
\text { Constant monitoring of blood levels not necessary } \\
\text { Hospitalization in intensive care unit not } \\
\text { necessary } \\
\text { No increase in serum osmolality, allowing this to } \\
\text { be used as surrogate for toxic alkohols levels in } \\
\text { following treatment }\end{array}$ & $\begin{array}{l}\text { Not available in all clinical setting } \\
\text { Expensive, approximately } \$ 5000 \text { per } 48-\mathrm{h} \\
\text { course of therapy } \\
\text { Intravenous preparation only available in } \\
\text { United Stated } \\
\text { Only formally approved by FDA for treatment } \\
\text { of metanol and ethylene glycol intoxication }\end{array}$ \\
\hline Etanol & $\begin{array}{l}\text { Inexpensive } \\
\text { Available in most clinical settings } \\
\text { Can be given intravenously or orally }\end{array}$ & $\begin{array}{l}\text { Lower affinity for alkohol dehy-drogenase than } \\
\text { fomepizole } \\
\text { Needs relatively high serum concentrations, } \\
\text { approximately } 100 \mathrm{mg} / \mathrm{dL} \text {, to compare saturate } \\
\text { the enzyme } \\
\text { Requires constant monitoring of blood levels } \\
\text { and possibly that of toxic alkohols } \\
\text { Hospitalization in ICU necessary during } \\
\text { treatment } \\
\text { Increases serum osmolality, hich can prevent } \\
\text { effective use of serum osmolality to monitor } \\
\text { response therapy } \\
\text { Impairs mentation, which can con-fuse } \\
\text { interpretation of response to therapy }\end{array}$ \\
\hline
\end{tabular}

Source: Kraut, 2008.

Giving vitamin B (including folic acid) is recommended to help clear methanol and toxic metabolites more quickly. Administration of high doses of folic acid can facilitate the breakdown of formic acid into carbon dioxide and water.

\section{METHODS OF RESEARCH}

The research design used was analytic observational with cross sectional approach. The study looked for the correlation between clinical diagnosis and serum methanol quality tests, and the correlation between $\mathrm{pH}$ levels, anion gap levels, osmolality levels and lactate levels with serum methanol levels. The location of the study was at RSU Dr. Saiful Anwar, Malang, East Java; and forensic laboratories of East Java Regional Police located in Surabaya. The time of the study was conducted in July 2016 - July 2018. The subjects of the study were patients with a diagnosis of suspected methanol poisoning in dr. Saiful Anwar, Malang, East Java during the period July 2016-July 2018 with the number of samples obtained as many as 29. Data is recorded in a special registry which is then collected and analyzed using normality test to determine the distribution of data and continued with Spearman correlation test to test the correlation between indirect laboratory results and Methanol levels. While the Fisher Exact test and Chi square test to examine the relationship between clinical diagnosis and qualitative test of serum methanol. The analysis program used is SPSS 20.

\section{RESULT AND DISCUSSION}

Characteristic of subjects can be seen in Table 3. Age of patients starts from 16-60 years with an average age of 28 years. According to sex, the mostly subjects were male as many as 24 people (83\%). The most common clinical symptoms were decreased consciousness $(41 \%)$ followed by blurred vision $(28 \%)$, while other complaints were dizziness, vomiting, abdominal pain without blurred vision or decreased consciousness by 
4\%. Based on the $\mathrm{pH}$ level, as many as 23 subjects $(79 \%)$ showed acidosis, while the rest $(21 \%)$ were normal or alkalosis. The results of measurements of lactate levels showed that most subjects (97\%) had levels above normal (> $2 \mathrm{mmol} / \mathrm{L})$.

Table 3 - Characteristics of research subjects

\begin{tabular}{|c|c|c|c|c|}
\hline Variable & Value & $\mathrm{n}(\%)$ & & \\
\hline Gender & & & \multirow{6}{*}{$\begin{array}{l}\text { Lactat }(\mathrm{mg} / \mathrm{dL}) \\
\text { Average } \\
\text { Median } \\
\text { Highest } \\
\text { Lowest }\end{array}$} & \multirow{6}{*}{$\begin{array}{l}9.68 \pm 5,33 \\
10.1 \\
17.9 \\
2.0\end{array}$} \\
\hline Female & & $5(17 \%)$ & & \\
\hline Male & & $24(83 \%)$ & & \\
\hline \multirow{3}{*}{$\begin{array}{l}\text { Domicile } \\
\text { Malang } \\
\text { Out side Malang }\end{array}$} & & \multirow{3}{*}{$\begin{array}{l}26(90 \%) \\
3(10 \%)\end{array}$} & & \\
\hline & & & & \\
\hline & & & & \\
\hline \multirow{5}{*}{$\begin{array}{l}\text { Age } \\
\text { Average } \\
\text { Median } \\
\text { Oldest } \\
\text { Youngest }\end{array}$} & & & \multirow{5}{*}{$\begin{array}{l}\text { Methanol }(\mathrm{mg} / \mathrm{dL}) \\
\text { Average } \\
\text { Median } \\
\text { Highest } \\
\text { Lowest }\end{array}$} & \multirow{5}{*}{$\begin{array}{l}6,09+9,55 \\
4 \\
50 \\
0\end{array}$} \\
\hline & $28.75 \pm 9,5$ & & & \\
\hline & & & & \\
\hline & 60 & & & \\
\hline & 16 & & & \\
\hline \multirow{5}{*}{$\begin{array}{l}\text { Clinical } \\
\text { Blurred vision } \\
\text { Decrease of consciousness } \\
\text { Blurred vision + Decrease of consciousness } \\
\text { Etc }\end{array}$} & & \multirow{5}{*}{$\begin{array}{l}8(28 \%) \\
12(41 \%) \\
5(17 \%) \\
4(14 \%) \\
\end{array}$} & \multirow{5}{*}{$\begin{array}{l}\text { Osmolaritas }(\mathrm{mOsm} / \mathrm{kg}) \\
\text { Rerata } \\
\text { Median } \\
\text { Highest } \\
\text { Lowest }\end{array}$} & \multirow{5}{*}{$\begin{array}{l}350.2 \pm 29.28 \\
351.4 \\
413.7 \\
305.3\end{array}$} \\
\hline & & & & \\
\hline & & & & \\
\hline & & & & \\
\hline & & & & \\
\hline \multicolumn{3}{|l|}{$\mathrm{pH}$} & & \\
\hline Average & $7.06 \pm 0,27$ & & & \\
\hline Median & 7.05 & & & \\
\hline Highest & 7.47 & & & \\
\hline Lowest & 6.57 & & & \\
\hline \multicolumn{3}{|l|}{ Anion Gap (meq/L) } & & \\
\hline Average & $18.90 \pm 10,4$ & & & \\
\hline Median & 20.31 & & & \\
\hline Highest & 44.78 & & & \\
\hline Lowest & 1.40 & & & \\
\hline
\end{tabular}

The results of the qualitative examination of methanol in the blood obtained 22 subjects with positive methanol intoxication (75.8\%). Based on clinical diagnosis, subjects suspected of methanol intoxication were 25 people $(86.2 \%)$. While the quantitative examination found that the value of methanol in subjects who tested positive from a qualitative examination was the highest of $50 \mathrm{mg} / \mathrm{dL}$, the lowest was $0 \mathrm{mg} / \mathrm{dL}$, and the average was $6.10 \mathrm{mg} / \mathrm{dL}$. Cross tabulation of qualitative results of methanol in serum and clinical diagnosis is presented in Table 4.

Table 4 - Cross tabulation of Methanol quality test with Clinical Diagnosis

\begin{tabular}{|c|c|c|c|c|}
\hline \multicolumn{2}{|c|}{$\mathrm{n} / \mathrm{n}$} & \multicolumn{2}{|c|}{ Methanol } & \multirow{2}{*}{ Total } \\
\cline { 3 - 5 } & Negatif & $1(14.3 \%)$ & $3(13.6 \%)$ & $4(13.8 \%)$ \\
\cline { 3 - 5 } Clinical & Positif & $6(85.7 \%)$ & $19(86.4 \%)$ & $25(86.2 \%)$ \\
\hline \multicolumn{2}{|c|}{ Total } & $7(100 \%)$ & $22(100 \%)$ & $29(100 \%)$ \\
\hline
\end{tabular}

In table 4 it can be seen that the proportion of subjects suspected to be positive based on clinical diagnosis was not different in the group with negative methanol $(85.7 \%)$ and positive methanol $(86.4 \%)$. The results of the test using Fisher's Exact test showed that the results of $p=0.692$ or greater than $\alpha=0.05$, hence there is no significant difference in the results of the examination using clinical diagnosis and examination of methanol levels in the blood. If continued with the analysis using diagnostic tests, the clinical diagnosis of methanol intoxication has a sensitivity value of $86.4 \%$ and a positive predictive value of $76 \%$ so that it can be said that clinical diagnosis has a good ability to detect methanol intoxication. However, the specificity value is only $14.3 \%$ and a negative predictive value of $25 \%$ which means that the clinical diagnosis used is not good enough to rule out that those who do not experience symptoms and sign of methanol intoxication. 
The results of the data distribution test using Shapiro Wilk test showed that there were 2 variables which were not normally distributed, namely Methanol and Lactate with a value of $p<0.05$ so that the Spearman correlation test was performed. Result of the test can be seen in table 5.

Table 5 - The results of the correlation test of methanol levels with $\mathrm{pH}$, Lactate, anion gap and osmolality using Spearman correlation

\begin{tabular}{|c|c|c|}
\hline $\mathrm{n} / \mathrm{n}$ & Correlation coefficient & $\mathrm{p}$ Value \\
\hline $\mathrm{pH}$ & -0.725 & $<0.001$ \\
\hline Lactat & 0.461 & 0.012 \\
\hline Anion gap & 0.633 & $<0.001$ \\
\hline Osmolality & 0.457 & 0.013 \\
\hline
\end{tabular}

Table 5 shows that there is a significant correlation between serum methanol levels with ph, lactate, anion gap and osmolality. The strength of the relationship between serum methanol levels and $\mathrm{pH}$ and anion gap is relatively strong, while the strength of the relationship between serum methanol levels and lactate and osmolality is sufficient. Serum methanol levels are inversely proportional to the $\mathrm{pH}$ value, which means that the higher the serum methanol level, the lower the $\mathrm{pH}$ value in the subject's blood.

Methanol poisoning often results from the consumption of a mixture of alcoholic beverages or the local term "oplosan" which contains methanol. Often there is a misperception that methanol is considered the same as ethanol. The number of reports of cases of death as a result of methanol poisoning indicates that the level of methanol consumed is quite high. During this time clinicians, especially those working in peripheral areas or at primary health care facilities, often make a diagnosis based on the presence of an history of drinking and accompanied by complaints and / or clinical symptoms namely blurred eyes and / or decreased consciousness. Challenges arise when patients who are brought or come to the emergency room are not accompanied by a clear disease history either because the patient does not want to admit or the condition of the patient is not known by the introduction / family (for example in boarding teenagers or people working outside the city). In cases where the history and clinical symptoms are not specific it is necessary to add additional investigations in this case laboratory tests. The problem that arises to date is direct laboratory test, namely serum methanol levels in the blood or determination of formic acid levels in the blood requires examination with a special tool that is very rarely found and the cost is quite expensive, so it needs alternative laboratory tests that are more practical and affordable.

Indirect laboratory test chosen by researchers in this case is blood gases analysis, blood sugar, BUN, serum creatinine, serum electrolytes and lactate. These indirect laboratory tests are relatively easier to be available in hospitals compared to direct laboratory test. From the examination of blood gas analysis, we can obtain $\mathrm{pH}$ and $\mathrm{HCO}-$ values, while the electrolyte value will be used to calculate the anion gap value. Blood sugar levels, BUN and sodium levels will be used to calculate the osmolality of blood serum.

Based on the results of research conducted at the emergency department of RSU Dr. Saiful Anwar Malang, it was found that patients who met the diagnosis criteria suspected of poisoning experienced the most complaints of decreased consciousness $(41 \%)$ followed by sudden blurred vision $(27 \%)$, while those who suffered both were $17 \%$. This is in accordance with the reference which states that the organ that is the main target of damage caused by methanol is the eye and brain nerves (Cohen, JP, 2016; White, 2008; Shusterman, D. and Ambre, J., 2007; Hofman, 2007; Mahanan, 2002) Formic acid will directly damage the distal / orbital part of the eye's nerves. Whereas in the brain, damage occurs in the basal ganglia. Damage caused by formic acid will cause visual disturbances (blurred eyes) and decreased consciousness.

Based on the Central Bureau of Statistics, the intended productive age is between 1564 years. In this study patients who came or were referred to RSU Hospital Dr. Saiful Anwar Malang with an initial diagnosis of suspicion that methanol intoxication is mostly in this age 
range with the youngest age of 16 years and the oldest age is 60 years. This is in line with the survey data conducted by RISKESDAS (Basic Health Research) in 2007 regarding the prevalence of alcohol drinkers, which states that the highest prevalence in the age between 15-24 years and decreases with age. The lowest prevalence is under 15 years and above 75 years.

Research data shows that almost all patients are male (82\%). This is consistent with a survey conducted by RISKESDAS in 2007 regarding the preference of alcohol drinkers in 27 provinces in Indonesia which showed that most of the prevalence in men was higher. This higher prevalence of male in alcohol drinker is also shown globally in the world. Differences in prevalence in gender are due to socio-cultural factors and economic levels. Women will get a negative image if drinking alcohol (Suhardi, 2011) and other factors such as pregnancy (Wilsnack, 2009).

The results of this study showed that the most complaints in patients were decreased consciousness and blurred vision but there was no significant relationship between clinical diagnosis findings and qualitative results of serum methanol examination. To obtain a more detailed explanation of the relationship between clinical diagnosis and qualitative levels of methanol, a diagnostic test was performed. The test results in clinical diagnosis, if positive, will have a good diagnostic value to detect methanol intoxication but if it is negative, it has a disadvantage, namely the possibility of a greater false negative. Of the two tests on this clinical diagnosis, the impact is, if only relying on clinical symptoms alone there will be many patients who are not diagnosed in early stages, hence they will not be managed properly, because these clinical symptoms appear at a late stage so handling will be much more difficult and more complicated (Nand, 2014).

In laboratory tests, the $\mathrm{pH}$ is measured in units of numbers, the more acidic the blood condition, the smaller the number and reversely. This study shows a significant relationship between $\mathrm{pH}$ levels and methanol levels in reverse. Correlation between Methanol levels and $\mathrm{pH}$ shows a negative relationship or increased levels of Methanol will further reduce the patient's $\mathrm{pH}$ level. This can occur because the metabolism of methanol will produce formic acid and formaldehyde which is strong toxic and causes severe metabolic acidosis (Hofman, 2007). The higher the level of serum methanol will increase levels of metabolites that are formed, namely formaldehyde and formic acids, so the blood will be more acid.

In this study, there was a significant correlation between Anion Gap values and serum methanol levels. We know that cations in blood serum will be balanced by anions. In laboratory tests, not all cations and anions can be measured. Cation levels are usually higher than measured anions. Serum cations that can be measured are $\mathrm{Na}^{+}$while the anions that can be measured are $\mathrm{Cl}^{-}$and $\mathrm{HCO}^{-}$. the difference in measurement between cations and anions is called Anion Gap (AG). This AG consists mostly of serum proteins, phosphates, sulfates, organic acids and conjugated ketoacids (Cohen, J.P, 2016). Formic acid and formaldehyde acid are organic acids, so the higher serum methanol level, more formic acid and formaldehyde acid are formed and this will increase the Anion Gap level.

This study shows that there is a significant correlation between lactate levels and serum methanol levels. There are two processes that cause lactate levels to increase, namely: first, formic acid that enters the cellular level will inhibit the process of oxidative phosphorylation so that the metabolism that occurs is anaerobic metabolism and will produce lactate (Hofman, 2007). Second, an increase in the NADH / NAD ${ }^{+}$ratio will drives the conversion of pyruvate to lactate (Mycyk, 2015).

This study shows that the osmolality value is directly proportional to the serum methanol level. In methanol intoxication patients there will be an increase in osmolal gap because the active methanol molecule is also a determining factor in increasing the osmolal gap. In osmolal gap measurement, it is necessary to examine serum osmolality which is very rarely owned by the hospital, therefore in this study the measured osmolality of the serum count (through the formula Oms $=[2 x \mathrm{Na}]+\mathrm{BUN}+2.8$ [glucose +18$]+($ methanol $/ 3,2)+$ (ethanol / 4,6) (Cohen, JP, 2016). Cohen also mentions that 1 milligram $/ \mathrm{dL}(0.3 \mathrm{mmol} / \mathrm{L})$ of methanol will increase serum osmolality by $0.34 \mathrm{mOsm} / \mathrm{kg} \mathrm{H} 2 \mathrm{O}$. 
In this study showed that clinical diagnosis is not strong enough and additional indirect laboratory tests (BGA, electrolytes, lactate) are needed. In addition, in some cases, methanol poisoning patients come without a clear anamnese and require additional investigations in addition to clinical symptoms. In this matter, High Anion Gap Metabolic Acidosis (HAGMA) and patient complaints (myopic eyes and decreased consciousness) can help clinicians to diagnose methanol intoxication (Cohen, J.P, 2016). But this study shows that is not only Anion Gap but also serum $\mathrm{pH}$, lactate and osmolality correlate significantly with serum methanol level. Compared to direct laboratory examinations (checking methanol levels), indirect laboratory tests are cheaper and easier to do. Hence, it will help clinicians to treat patients faster properly.

Based on this study, clinicians are advised not only to use clinical diagnosis but also to use additional other investigations such as $\mathrm{pH}$, Lactate, electrolytes (to calculate Anion Gap) and serum osmolality to help establish a diagnosis of methanol intoxication. History of drinking liquor coupled with clinical symptoms of nearsightedness and / or decreased awareness is indeed strong to diagnose methanol intoxication but if there are no clinical symptoms it is not certain that methanol intoxication does not occur so investigations are needed namely blood gas, electrolyte and lactate analysis.

What has not been explained in this study is the correlation between simple laboratories such as the number of leukocytes (white blood cells) which tend to increase (Shadnia, 2013). In this study also can't be explained or measured which variable is the most strong correlation because the $p$ value between variables does not indicate the level of strength of the correlation between variables.

The limitation in this study is that it cannot get rid of other co ingestion because of the limitations of laboratory test. This study also has not been able to calculate the correlation between duration time (time of the first appearance of a signs and symptoms) with serum methanol levels because of the difficulty of obtaining accurate data regarding the first time the patient drank methanol.

\section{CONCLUSION}

Based on the results and discussion of the research described above before, there are some conclusions that can be drawn from this study namely; there is no correlation between clinical diagnosis and qualitative levels of serum methanol. This correlation is mainly at low sensitivity when compared between clinical diagnosis and qualitative levels of serum methanol. There is a significant correlation between indirect laboratory tests $(\mathrm{pH}$, osmolality, anion gap and HCO3-) with quantitative levels of serum methanol. With this significant relationship, the indirect examination can be used as a diagnostic tool for clinicians.

Suggestion. Based on the conclusions above, some of the things suggested from this study are: the government must increase the socialization of the dangers of alcoholic drinks to the public so that no more victims arise. Improving training for clinics in primary health facilities in determining the diagnosis of methanol poisoning with the help of simple investigations. Increase research in the field of diagnostic testing of methanol poisoning so that patients with suspicion of methanol intoxication can be identified and treated appropriately.

\section{REFERENCES}

1. Cohen, J. P., and Quan, D. (2016). Alcohols. Cohen, J.P's Emergency Medicine: AComprehensive Study Guide (8th Ed). New York: McGraw-Hill.

2. Dorokhov, Y .L., Shindyapina, A. V., Sheshukova, E. V., and Komarova, T. V. (2015). Metabolic methanol: molecular pathways and physiological roles. Physiological reviews, 95(2), 603-644.

3. Fulde. (2014). Emergency Medicine: The Principles of Practice (6th Ed). Australia: Elsevier. 
4. Guyton, A. (2006). A Textbook of Medical Physiology: Metabolism of Carbohydrate and Formation of Adenosine. Philadelpia: Elsevier Inc.

5. Hodgson, E. (2004). A Textbook Of Modern Toxicologic. Canada: A John Wiley \& Sons, Inc.

6. Hoffman, R. S. (2007). Gold Frank Manual Of Toxicologic Emergencies. USA: The McGraw-Hill Companies, Inc.

7. Jammalamadaka, D., and Raissi, S., (2010). Ethylene glycol, methanol and isopropyl alcohol intoxication. The American journal of the medical sciences, 339(3), 276-281

8. Brent, J. (2015). Translational Antidote Research: A Bedside to Bench Tale Asia Pacific. Journal of Medical Toxicology, 4(1), 9-12.

9. Kraut, J. A., and Kurtz, I. (2008). Toxic alcohol ingestions: clinical features, diagnosis, and management. Clinical Journal of the American Society of Nephrology, 3(1), 208-225.

10. Manahan, S. (2002). Toxicological chemistry and biochemistry. USA: CRC Press.

11. Methanol Institute. (2008). Methanol Safe Handling Fact Sheets. San Diego California: . Methanol Institute.

12. Mokhlesi, B. (2007). Adult Toxicology in Critical Care, Part II: Specific Poisonings. Journal of the American College of Chest Physicians (CHEST), 897-922.

13. Mulyadi, M. (2014). Darurat Miras Oplosan. Pusat Pengkajian, Pengolahan Data dan Informasi (P3DI), 4(24), 9-12.

14. Mycyk, M. B. (2014). Toxic Alcohols. Lange Medical: Clinical Emergency Medicine. New York: Mc Graw Hill.

15. Mycyk, M. B. (2015). Harrisons Principles of Internal Medicine: Poisoning and Drug Overdose. USA: Mc Graw Hill.

16. Nand, L. (2014). Methyl Alkohol Poisoning: A Manifestation of Typical Toxicity and Outcome, Journal Of The Association Of Physicians Of India, 62, $96-102$.

17. Poznyak, V., and Rekve, D. (2014). WHO: Global Status Report on Alkohol and Health. Luxemburg: WHO.

18. Rao, N. G. (2010). Textbook of Forensic Medicine and Toxicology. India: aypee Brothers Medical Publishers (P) Ltd.

19. Rath, A. (2016). Methanol Poisoning. Retrieved from http://www.orpha.net/on June.

20. Salocks, C., and Kaley, K. B. (2003). Technical Support Document: Toxicology Clandestine Drug Labs/Methamphetamine. California Environmental Protection Agency: OEHHA.

21. Shadnia. (2013). Role of Clinical and paraclinical manifestations of methanol poisoning in outcome prediction. Journal of Research in Medical Science, 865-869.

22. Shusterman, D., and Ambre, J. (1997). V Case Studies in Environmental Medicine.

23. Suhadi. (2011). Preferensi Peminum Alkohol di Indonesia Menurut Riskesdas tahun 2007, Pusat Teknologi Terapan Kesehatan dan Epidemiologi Klinik. Buletin Penelitian Kesehatan, 39(4), 154-164.

24. Cohen, J. P. (2015). Cohen, J.P's Emergency Medicine: A Comprehensive Study Guide (7th Ed). USA: Mc Graw Hill.

25. Wilsnack, R., et al. (2009). Gender and Alcohol Consumption: Patterns from The Multinational Genacis Project. NIH author manuscript, 104(9), 1487-1500.

26. White, S. R. (2008). Rosen's Emergency Medicine (8th eEd). Philadelphia: philadelphia press.

27. WHO. (2014). Methanol Poisoning Outbreaks. Geneva: WHO Secretariat.

28. Zhang, G., Crews, K., Wiseman, H., Bates, N., Hovda, K. E., Archer, J. R., and Dargan, P. I. (2012). Application to include fomepizole on the WHO model list of essential medicines. WHO: Medical Toxicology and Information Services. 